CIUDAD Y TERRITORIO

ESTUDIOS TERRITORIALES

ISSN(P): 1133-4762; ISSN(E): 2659-3254

Vol. LII, № 206, invierno 2020

Págs. 791-804

https://doi.org/10.37230/CyTET.2020.206.05

CC BY-NC 4.0

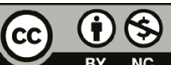

\title{
Barrios en ladera, Mieres (Asturias): entre la aldea y la autoconstrucción marginal
}

\author{
Sergio Tomé-Fernández ${ }^{1}$
}

Profesor Departamento Geografía Universidad de Oviedo.

\begin{abstract}
RESUMEN: Se analiza la evolución reciente, situación actual y necesidades de los barrios en pendiente de la ciudad de Mieres (Asturias), que albergaron históricamente buena parte del hábitat de las clases bajas, en las vertientes menos accesibles y de peores condiciones ambientales. Carentes de investigaciones específicas, poseen gran interés y valor ejemplarizador por su peso espacial, dimensión histórica, diversidad, originalidad formal, y por el efecto que en ellos ha tenido la reconversión minera e industrial, al tratarse de una shrinking city. Se realiza una aproximación geográfica de conjunto, apoyada en el trabajo de campo, entrevistas, documentación urbanística y catastral, bibliografía y estadísticas demográficas. El diagnóstico resultante pone de manifiesto comportamientos localmente dispares, desde la gentrificación al deterioro, con una multiplicación exponencial de los edificios abandonados. Como conclusión fundamental puede establecerse la necesidad de una acción regeneradora que tenga en cuenta las especificidades locales y la casuística diversa en el interior de esos organismos urbanos, si quiere atender objetivos sostenibles y de equidad espacial.
\end{abstract}

PALABRAS CLAVE: Asentamientos en pendiente; Shrinking cities; Regeneración urbana; Accesibilidad.

\section{Hillside Neighbourhoods, Mieres (Asturias): between the village and marginal self-construction}

ABSTRACT: This article analyzes the recent evolution, the current situation and the needs of the elevated districts in the city of Mieres (Asturias). There, historically the lower class occupied the elevated areas with the worst access and adverse environmental conditions. They have not been studied despite their interest in size, internal diversity, history and morphology. The effect that mining and industrial reconversion has on them is also important, since Mieres is a shrinking city. The article makes a comprehensive geographical approach, based on field work, urban and property documents, bibliography and demographic statistics. The diagnosis obtained indicates different evolutions within the study area, from gentrification to deterioration, with a multiplication of the abandoned buildings. In conclusion, a regenerative action adapted to local conditions and the internal diversity of this type of urban organisms is needed, in order to achieve equity and sustainability.

KEYWORDS: Sloping urban settlements; Shrinking Cities; Urban Regeneration; Accesibility.

Recibido: 24.09.2019; Revisado: 28.11.2019

Correo electrónico: stome@uniovi.es; NN ORCID: https://orcid.org/0000-0001-8741-7017

El autor agradece los comentarios y sugerencias realizados por los evaluadores anónimos, que han contribuido a mejorar y enriquecer el manuscrito original.

1 Este trabajo es una aportación al proyecto «Paisajes de la Desigualdad en la Periferia de las Ciudades», del Programa Estatal de Generación de Conocimiento y Fortalecimiento Científico y Tecnológico del Sistema de I+D+I, referencia PGC2018-098209-B-100. 


\section{Introducción y Metodología}

E n España faltan estudios locales a partir de los cuales pueda realizarse un acercamiento de conjunto a los barrios de clase baja situados en topografías muy inclinadas, cuyas problemáticas ofrecen enorme interés. Este texto pretende alimentar el debate sobre la intervención en esa clase de espacios, que ya cuenta con algunas contribuciones como las presentadas a las jornadas "Barrios Pendientes", celebradas en 2018 en Las Palmas de Gran Canaria (Ayuntamiento de las Palmas, 2018). La aportación que aquí se ofrece es el análisis de un ejemplo cualificado, provisto de cierto valor general, entre otras razones por corresponder a una ciudad menguante. En efecto, los asentamientos en ladera actúan como envolvente del casco de Mieres, al igual que ocurre con otras poblaciones cercanas en el mismo valle del río Caudal o el del Nalón (Langreo), definidores de la Cuenca Central Hullera asturiana. Forman, en torno al distrito urbano de Mieres, un conjunto difuso, de composición compleja, individualizado formalmente y bien visible desde la parte baja, excepto cuando son construcciones aisladas entre masas de arbolado. Su base organizativa es el entramado de aldeas y lugares de antiguo origen, a las que se superpuso el estrato minero e industrial, mediante un proceso de crecimiento muy rápido y, excepto en sus inicios, también muy poco sujeto a reglas. La fase de mayor aceleración coincide con la Dictadura de Franco, durante la cual el planeamiento se centró en la vega, dejando que la improvisación y dispersión de iniciativas dominasen el desarrollo final de las partes elevadas. En consecuencia, una fracción considerable del conglomerado resultante es todavía hoy la parte más pobre y más deficiente de la ciudad en términos urbanísticos, características que no retratan a la totalidad pues se trata de un medio bastante contrastado. Las reformas del periodo democrático han surtido más efecto en el núcleo fundamental de la ciudad que en su parte alta, de manera que la Estrategia de Desarrollo Sostenible e Integrado de Mieres la considera un espacio pendiente de recuperación (CECODET, Centro de Cooperación y Desarrollo Territorial, 2016).

En relación con ello, también se trata de la pieza menos conocida del área urbana, a pesar de que precisamente allí los efectos del declive económico han sido particularmente graves y se perciben mejor, en forma de activos ociosos. Atendiendo a esa necesidad, lo que aquí se ofrece es la caracterización geográfica global, el análisis de las dinámicas urbanas actuales y la observación de las diferentes problemáticas, teniendo en cuenta la riqueza de matices y la diversidad interna. Como premisa de partida debe aceptarse que sin esa información no es posible plantear eficazmente la acción rehabilitadora, en beneficio de la comunidad. El área de estudio coincide con el borde urbano y la primera orla periférica, donde el influjo de la ciudad pesa más que la ruralidad. Allí se ha abierto un fichero de los barrios y aldeas situados en el plano inclinado, más los que teniendo una posición de bisagra con el fondo de valle poseen carácter similar, cuando no están más deteriorados. Hasta cierto punto, la originalidad del sistema radica en la dispersión de sus componentes y la relativa variedad morfológica y social que presentan, aunque siguen en gran medida un mismo patrón (planta, usos, jerarquización interna) que permite compararlos.

La escala y la naturaleza del espacio analizado, cuyas especificidades no siempre son fáciles de documentar o cuantificar a distancia, determinó que obtuviesen preferencia los reconocimientos sobre el terreno, practicando conteos que permitieron contrastar o completar la información catastral. Los recorridos fueron aprovechados para entrevistar a una treintena de residentes de distinta generación, un tercio aproximado por cada tramo de edades, repartidos entre el $60 \%$ de los núcleos estudiados. Se utilizó al efecto un cuestionario semiestructurado con preguntas referidas a la experiencia geográfica del entrevistado, la evolución reciente del asentamiento y sus déficits, en términos funcionales y de habitabilidad. La explotación de los resultados puso de relieve percepciones relativamente coincidentes por edad y grupo social, empleadas (en el capítulo cinco y secundariamente en otros apartados del texto) para enriquecer o matizar el acercamiento. Las otras fuentes y recursos utilizados fueron los habituales en la investigación geográfica: bibliográficos, hemerográficos, estadísticos (Catastro, Padrón, Nomenclátor) y relativos al planeamiento urbano, además de Google Maps. El condicionante topográfico, y el efecto de los ciclos de crecimiento propios de comarcas dedicadas a la extracción de carbón, dejaron un sistema de núcleos con definiciones muy características (MAURíN, 1987). Dentro de ellos, las herencias arquitectónicas resultan enormemente ricas y contrastadas, siguiendo una serie temporal (desde lo rural a lo urbano) que ha llegado a nosotros bastante bien conservada, debido en parte a la decadencia del valle. La metodología aplicada tomó entonces como punto de partida esa materialidad del paisaje, mediante la cual resulta más fácil comprender la interacción espacial entre las distintas piezas urbanas, y acceder a la lógica que preside las relaciones entre las formas, los usos económicos y los contenidos socio demográficos. A la hora de realizar el diagnóstico, la peculiar 
configuración del área de análisis obligó a trabajar en las escalas meso y micro, para fijar el papel de los factores geográficos en las casuísticas locales, buscando una aproximación dialéctica a las dinámicas de opuestos: abandono y regeneración.

Algunos de los residentes entrevistados, con menos edad y más formación, llamaron favelas a las zonas de ese tipo, como también ocurre en Bilbao. Pero no es un concepto generalizado, como sí lo está la denominación de barracas para las habitaciones obreras, igual que barracos en portugués. Aplicado a Mieres, el vocablo favela sólo es utilizable en sentido metafórico, por la verticalidad y la concentración de rentas bajas. Con viviendas y urbanismo de baja calidad, resultantes de la suma de iniciativas desconectadas, donde la participación del sector público ha sido baja. La distancia es sideral con respecto a los barrios informales, fruto de la ocupación masiva, en países latinoamericanos (MAKHLouf, 2015; MilLán \& Puentes, 2019). Pero pueden encontrarse indudables correspondencias, con asentamientos maduros de menor precariedad, en lo relativo al sustrato inadecuado (SANTA María, 2011), la vulnerabilidad ambiental (DAvIs, 2017), el peso de la inmigración o la auto construcción (Esdras, 2008). Claro está que las favelas brasileiras, como los slums de otros lugares, no necesariamente aparecen en alto.

Los barrios de casas colgadas tienen una participación sustantiva en diversas ciudades españolas, caso de Bilbao ya mencionado, donde existen núcleos de gran similitud con los de Mieres como Peñascal, procedentes de la parte central del siglo XX. Pero otros distritos escarpados de la aglomeración del Nervión forman parte de la ciudad compacta y acogen toda clase de morfologías, incluso edificación cerrada o abierta y en altura, como también sucede en Vigo (GoBIERNo de España, 2011). Los Riscos de Las Palmas de Gran Canaria son en cambio una pieza integrante del centro histórico, así que su edad y la presencia de pervivencias materiales de valor cultural resultan emparentables con el valle del Caudal, aunque en la isla se trata de espacios mejor integrados físicamente, con tejidos más densos y continuos (Alumnos del Colegio Claret, 2010; Geursa, 2019). Además, la renovación del caserío primigenio ha tenido allí mayor intensidad, igual que en los barrios formados durante el siglo XX a partir de parcelaciones particulares en terrenos pendientes de Santa Cruz de Tenerife o Puertollano (CAÑIZAREs, 2001, García \& PuLIDo,1980). Esa comparativa proporciona las primeras claves de la personalidad geográfica del conjunto mierense, compartida en términos generales con la cercana Langreo (AYUNTAMIENTO DE LANGREO, 2011).

\section{La singularidad geográfica de un sistema complejo}

Notable ejemplo de ciudad menguante, Mieres del Camino (22.741 habitantes en 2020) es la capital de un municipio que pasó de 70.871 habitantes en 1960 a 37.959 en 2020 (RodRiguez \& MENÉNDEZ, 2019). Ocupa el fondo del estrecho valle del río Caudal (861 metros de sección en su parte más amplia, frente a 283 en la más angosta) y, de forma discontinua, la zona baja y media de las abruptas vertientes que lo flanquean, a lo largo de más de seis kilómetros. Es el cuerpo principal de una pequeña conurbación longilínea que se extiende siguiendo el valle y los de sus afluentes, dentro del término municipal (RodRígueZ \& MENÉNDEZ, 2005). Hasta el despegue de la minería del carbón y la siderurgia, cristalizado en 1880 con los altos hornos de la Fábrica de Mieres, la vega fue un espacio de cultivo (MORO, 2014:9; FonsECA, 1995:516; MAURín, 2011). Para respetarlo, y quedar a salvo de las crecidas, las tres poblaciones preindustriales (Oñón, Requejo, La Villa) que son el germen de la población y de su trama polinuclear y lineal, se situaron en el contacto con la ladera oriental, sobre la carretera de Castilla (1790) (GARCIA, 1995: 312; Fernández, 2015: 320; Pérez, 1982: 321).

Forzosamente las infraestructuras de transporte y los usos extractivos o productivos terminaron colonizando el escaso terreno llano de la ribera, cuya fracción más valiosa, situada en la margen derecha, fue reservada para las rentas altas mediante los dos primeros proyectos de Ensanche $(1900,1924)$ (PÉREZ, 1980). El proletariado se estableció de forma más improvisada o precaria en los rebordes próximos a elementos de rechazo y en las laderas, siguiendo la malla de los caminos y la red de poblamiento rural, donde aldeas como Siana o La Rebollada batían récords de crecimiento en 1930 y 1940 respectivamente (PÉREZ, 1982: 79, 112). La eclosión de posguerra obligó a urbanizar un tercer Ensanche (1948) y edificar dos barriadas obreras (Santa Marina y San Pedro) en la parte libre y menos apreciada de la vega, llevando el concejo como ya se dijo a su máximo histórico en 1960. Las necesidades de alojamiento desatendidas obligaron a generalizar la auto construcción en las vertientes, modelando barrios vulnerables que heredará la Democracia (CAstelli, 1996; Hernández \& al., 2011).

Iniciada durante el último tercio del siglo XX, la reconversión económica ha convertido a Mieres en una shrinking city, pese al esfuerzo reindustrializador que le ha hecho perder menos empleos que habitantes, atraídos por Oviedo y Gijón (GANCEDO, 2019). La colmatación de la vega culminó, al final de la Dictadura y particularmente a su caída, con la puesta en marcha de tres polígonos industriales que bordean el casco por el lado norte (Fábrica 


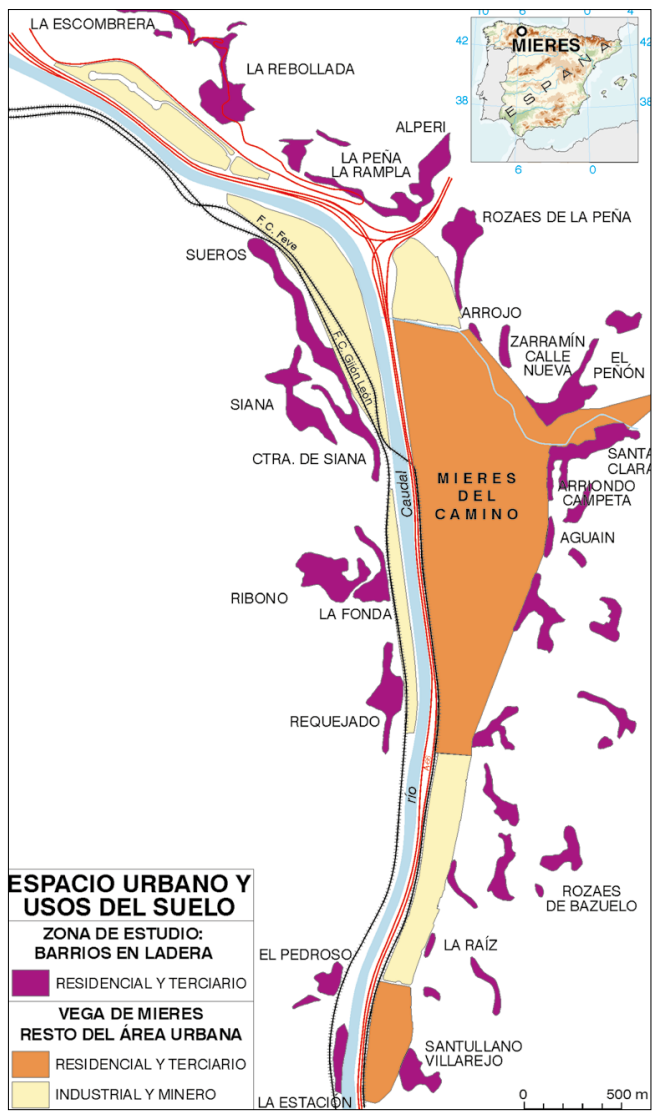

FIG. 1/ Sistema de asentamientos en las vertientes de Mieres, con expresión de los usos.

Fuente: Elaboración propia a partir de Google Maps, cartografía y datos del CatAstro, INE y Ayuntamiento. De Mieres.

de Mieres, sobre la antigua siderurgia cerrada en 1966), sur (Vega de Arriba) y este (Gonzalín), más dos promociones residenciales de iniciativa oficial, Vega de Arriba (1.786 viviendas) y Nuevo Santullano (1.276). La mezcla de usos y una deficiente articulación entre las grandes piezas, acentuada por el trazado de las autopistas A-66 y AS-II, esta última con un complejo enlace a distinto nivel en La Peña, son rasgos destacables de la base del valle (GARCía, 1995: 326; Fernández. \& Fernández., 2016; RodRiguez \& MENÉNDEZ, 2019).

En contraposición con ella, la parte situada al piedemonte y en el plano inclinado tiene como principales atributos su mayor discontinuidad espacial, heterogeneidad formal y fragmentación, así como un peso superior de las pervivencias de interés cultural, pero también del hábitat informal. En efecto, el sistema de asentamientos objeto de análisis es atomizado y laxo, con 1.647 edificios (2.467 viviendas) repartidos entre 78 entidades de población (barrios, aldeas y lugares); de las cuales

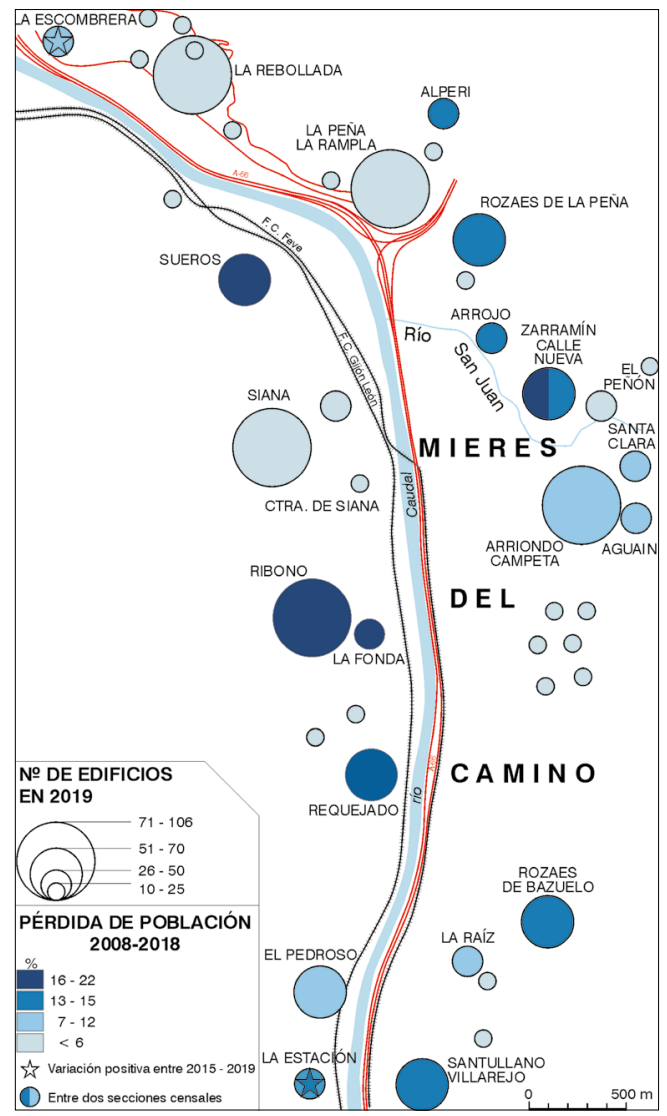

Fig. 2/ Masa edificada y evolución demográfica.

Fuente: Elaboración propia a partir del CATASTRO, INE y AYUNTAMIENTO de Mieres.

12 agrupan 50 o más casas, pero únicamente rebasan el centenar La Rebollada y el conjunto formado por La Fonda y Ribono (ver FIG. 1 y 2). Uno de cada tres no suma ni diez inmuebles y en gran medida son sólo caserías diseminadas, habiendo entre los núcleos, de límites difusos, extensos vacíos recubiertos por pradería y frondosos bosques mixtos. La margen izquierda del Caudal, segregada por el ferrocarril que discurre inmediato a la vertiente occidental, únicamente alberga un tercio del total de viviendas. El salpicado resulta más denso sobre la orilla opuesta, especialmente en la parte septentrional de la ladera este, cercana a la antigua siderurgia, y en su tramo central próximo al viejo Mieres, donde el declive del terreno no resulta tan disuasorio como aguas arriba. Las formas del relieve son el primer factor estructurante, que sitúa la mayoría de los principales núcleos a la entrada de los valles laterales, y ayuda a emplazarlos en las hombreras fluviales, los repechos o allí donde las pendientes se dulcifican, a una cierta altura (ver FIG. 3). 

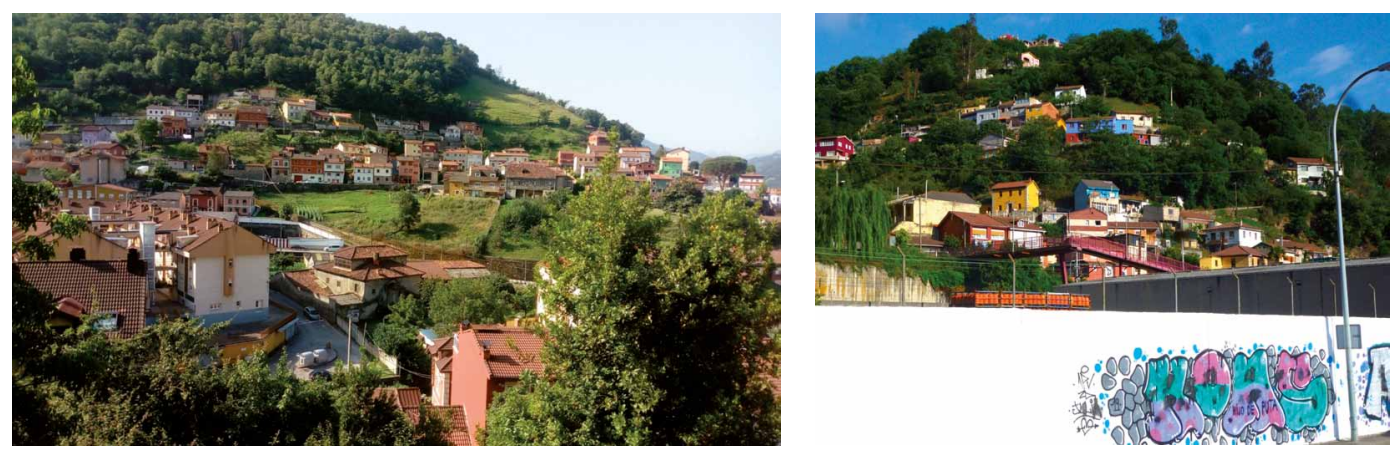

FIG. 3/ Poblamiento a la entrada de los valles laterales, en la vertiente oriental (Arriondo y Aguaín, arriba) y en la occidental (La Fonda y Ribono, abajo).

Fuente: Fotografía de Sergio TomÉ, 2019.

La caminería histórica, el reparto de los pozos hulleros (Barredo, Peñón, Terronal) y los centros fabriles, facilitaron la dispersión de un poblamiento donde se identifican fácilmente tres generaciones o etapas de desarrollo de los asentamientos. Por un lado, están los núcleos tradicionales de origen rural, vinculados en algunos casos al Camino de Santiago (Requejado, La Fonda, La Peña y La Rebollada, de sur a norte) (LEÓN, 1995: 35; VEGA, 2015: 72). Su figura es lineal, pero cuando la orografía lo permite suelen formar una agrupación apiñada, en torno a la iglesia o no. Lo natural es que al crecer configuren terrazas, peñas arriba o abajo, y disposiciones en cuña hacia los arroyos afluentes. El estrato siguiente lo aporta el ciclo minero del cambio de siglos XIX-XX, con influencia directa de la Fábrica de Mieres como propietario y promotor en La Rebollada o La Peña (CECODET, 2016: 87). Surgieron entonces parcelaciones y calles particulares en espacios adyacentes a las aldeas, márgenes de las carreteras y caminos rurales (caleyas). Articulados en hileras, los nuevos edificios aparecen descritos en la Topografía Médica de 1885 como "casas arrimadas a la montaña, de piso terreno, con cocina y dormitorio o una sola pieza" (MuÑIz, 1885: 38). Gracias a ese añadido las entidades de categoría superior desarrollaron composiciones longitudinales más complejas, con bifurcaciones y caminos superpuestos, en zigzag o en graderío (ver FIG. 4).

La otra fase más destacada en la génesis del poblamiento corresponde a la Dictadura franquista, especialmente durante la Autarquía. Primó lo que Solá Morales (SoLÁ, 1973: 24) llamaba "procesos marginales de urbanización", que densificaron los poblados previos y sembraron otros por toda la jurisdicción. La baja calidad urbanística y la sub integración se generalizaron, sin borrar la base rural que se adaptó a formas de vida mixtas. No todo fueron ni mucho menos asentamientos informales, pues el clasismo de la época introdujo formas de ocupación selectivas, que en el caso de Arriondo dan lugar a una pequeña ciudad jardín acomodada, de planta regular.

La totalidad del sistema se inscribe dentro de las llamadas laderas fonderas, que no sobrepasan los 440 metros, cuando las cumbres superan los mil (CECODET, 2016: 217). Una visión más próxima permite distinguir tres franjas altitudinales, de abajo arriba. La primera, agregada al casco, ocupa suelo plano del nivel de base (190-212 metros) y terrenos en declive por debajo de los 260 metros; reúne el $41 \%$ de los asentamientos con más peso espacial: Arriondo, El Pedroso, La Peña, Sueros y Santullano, asomados los tres primeros a los valles tributarios. El peldaño intermedio es el de aquellos barrios y aldeas en pendiente, cuya parte alta se sitúa entre 260 y 300 metros, caso de Aguaín, La Rebollada, Rozaes de la Peña y Requejado, por citar sólo los mayores. La aureola exterior comprende los núcleos donde el sustrato rural suele tener más peso y cuyo caserío está, al menos en parte, encaramado más arriba de los 300 (Ribono, Siana) o 400 metros (Rozaes de Bazuelo). Los desniveles dentro de un mismo término llegan a alcanzar los 63 metros (EI Somerón), 75 (Requejado) y hasta 114 en Ribono, pues la edificación se estratifica en cinco, seis o incluso nueve escalones discontinuos. Topónimos como La Peña, La Rampla, Despeñaperros o La Cuestona, dan idea de pendientes muy pronunciadas, que en accesos y conexiones internas (Vistalegre, Aguaín) sobrepasan ampliamente a las rampas más inclinadas de la carretera N-630 al remontar el puerto de Pajares hacia la Meseta ${ }^{2}$. 

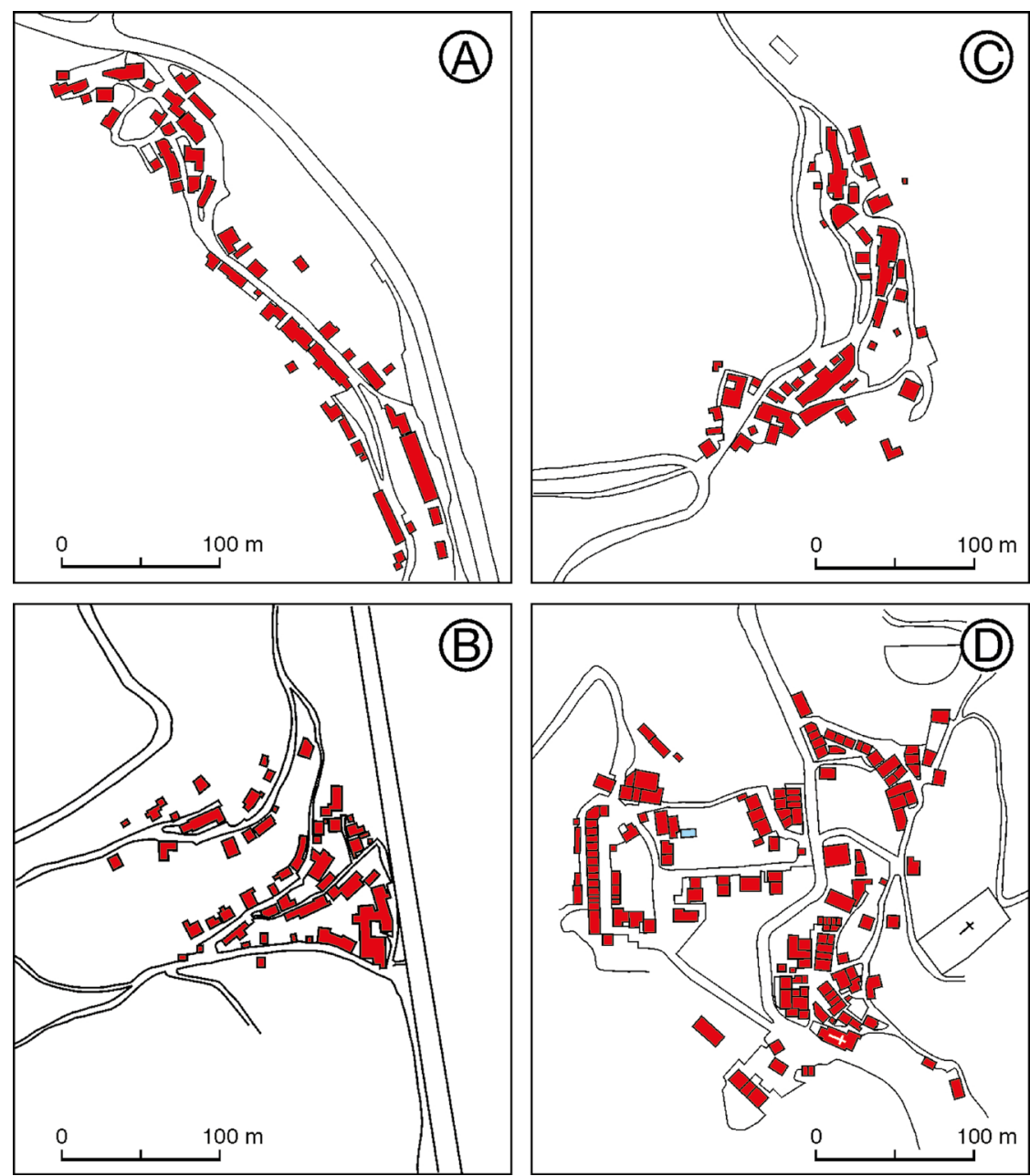

FIG. 4/ Tipología de núcleos: A. Lineal, adaptado a una hombrera fluvial (Sueros). B. En cuña (La Fonda).

C. Lineal con escalones, a media vertiente (Rozaes de Bazuelo). D. Mixto. Trama de pueblo-carretera vinculado al Camino de Santiago, con añadido de parcelaciones al oeste (La Rebollada).

Fuente: Elaboración propia a partir del CATASTRO.

\section{La diversidad tipológica, del patrimonio etnográfico a la auto construcción}

Las casas colgadas forman agregados heteróclitos, entre rurales y urbanos, que suelen seguir un mismo patrón edilicio. Las dataciones del Catastro, muy aproximativas en los bienes de más edad, atribuyen al $53 \%$ de las propiedades un origen anterior a la Guerra Civil, pero en seis de cada diez la intensidad de las reformas impide reconocer hoy trazas heredadas. Incluso así, hay más patrimonio histórico en la zona de estudio que en el centro, donde los núcleos originarios están muy desfigurados y el primer y segundo Ensanche perdieron gran parte de su arquitectura culta. La parte baja y media de las vertientes conserva cerca de 150 construcciones vernáculas, de carácter básicamente rural; las hay anteriores al siglo XIX, pero por lo regular parecen proceder de los años entre siglos o aún después, ya que el modelo perduró sin apenas variación hasta los años treinta. Son, en gran medida, casas tradicionales de corredor, muy vistosas cuando este es doble o en esquina, y están provistas de grandes aleros. Su gradación es notable, con sensibles diferencias entre las de mayor empaque, sobre fincas de cierta dimensión (Requejado) y las más sencillas, de tamaño exiguo (ver FIG. 5). Estas componen pequeños núcleos incompletos o discontinuos de gran interés etnográfico, a menudo bien cuidados (Siana, La Quinta, El Pedroso), donde quedan hórreos y algún hórreo-vivienda. 

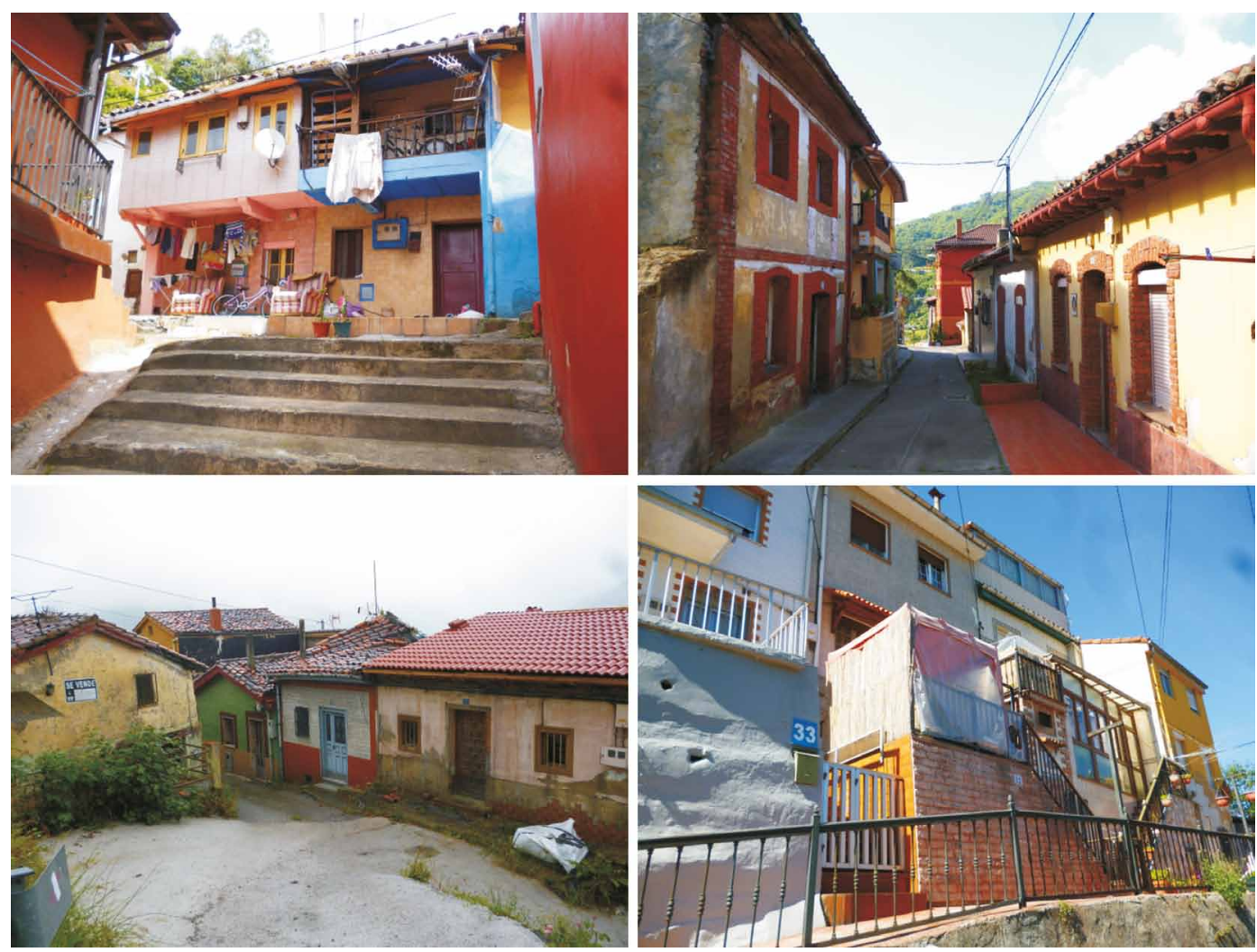

FIG. 5/ Casas de corredor (arriba izda.), barracas del cambio de siglos XIX-XX (arriba dcha.), alojamientos mínimos de posguerra (abajo izda.) y autoconstrucción (abajo dcha.)

Entre los inmuebles correspondientes al intervalo 1880-1936, más de dos centenares son de tipo más urbano, si bien pueden conservar elementos previos como los corredores. El grupo de mayor interés es el de las casas obreras denominadas en el valle barracas, de planta baja o planta y piso (raramente dos), con muros de ladrillo macizo o mampostería, revocada o al aire. Promovidas por empresas o particulares, de los que toman nombre (Casas de Fermín, de Alperi, de David), siguen principios higienistas y tienen como signo distintivo los marcos de las ventanas en ladrillo visto (ÁlvareZ, 1986: 88). La representación más nutrida puede verse en La Rebollada y en el entorno de la avenida de Sama (calle Nueva, La Belonga), donde se encuentra el callejón del Peñón, tipo ciudadela, cerca del cementerio.

La autoconstrucción y la micro vivienda precaria, de la que subsisten no pocas muestras, habitadas o no, también tiene su raíz en los mismos años. Sin embargo, su expansión se producirá durante la posguerra, periodo que aporta una quinta parte de las construcciones existentes hoy, igual porcentaje que la etapa desarrollista. Los años cuarenta y cincuenta añadieron nuevas promociones más sencillas del tipo barraca (casa molinera, en otras regiones), en su versión mínima (puerta y ventana) o de dos ventanas, con las cuales se incrementó el número de conjuntos de vivienda popular hasta un total de cuarenta y nueve. Dieciocho de ellos tienen cinco o más edificios formando cuerpo o barra, hasta un máximo de trece, y el resto son baterías de entre dos y cinco pabellones. Un 78\% del total están fechados entre 1892 y 1936, los demás son posteriores a la contienda.

Por otro lado, las condiciones del periodo más duro de la Dictadura hicieron proliferar como ya se dijo la auto construcción, hasta sumar más de doscientas unidades, distribuidas de tal modo que en algunas localidades (Lavadero, Ribono, Siana) representan casi un cuarto del parque inmobiliario. Se trata de un hábitat muy básico, de planta baja en un principio, al que se van adicionando elementos en función de las necesidades familiares: cuerpos alzados o pabellones 
laterales, así como terrazas y porches, abiertos o cerrados mediante aluminio acristalado, incluso un pequeño garaje cuyo techo cumple la función de azotea. Son característicos de la fisonomía final los revestimientos de alicatado, o compuestos por fragmentos de granito de distintos colores, así como los mástiles con la bandera o banderas y las figuras de piedra artificial (animales, floreros); estas suelen coronar los cierres de finca realizados mediante prefabricados de cemento, formando celosía. Las viviendas unifamiliares de status superior, no muy numerosas en esos parajes durante aquellas fechas, suelen aparecer en los entornos más accesibles o de condiciones ambientales favorables. En cambio, la arquitectura de edificación cerrada al estilo post racionalista sólo está presente en las vías principales de contacto con La Vega (La Peña, Arrojo), ámbito donde proliferó, con rasgos de cierta nobleza.

El armazón físico apenas posibilitó la inserción de grupos de bloques tipo barriada, con formación abierta, en Santa Ana y Rozaes de la Vega, ya durante los años sesenta. Destinados a mineros, distan poco del Lavadero del Batán. Esa década y la posterior trajeron consigo un progresivo incremento en la calidad de las promociones, especialmente cuando ocupan los lugares mejor situados (Santa Clara, Arriondo), en correspondencia con lo cual y a partir de un cierto nivel suelen responder a la idea de chalet. Por fin, los edificios de nueva planta fechados durante el periodo democrático no suman ni un $7 \%$ de la masa edificada total, a causa del declive urbano, pero también como consecuencia de la rehabilitación, a la que nos referimos luego. Son casas más ricas, por término medio (El Pedroso, El Rollu, Siana), pero también muy discordantes a veces con el caserío circunstante. Entre los impactos más característicos está el uso de colores saturados o chillones, también empleados habitualmente al restaurar fachadas antiguas (ver FIG. 6).

\section{Los procesos recientes, del abandono a la rehabilitación}

Dinámicas de opuestos tienden a establecer una diferenciación creciente, entre núcleos y dentro de cada uno de ellos. El conteo sobre el terreno arrojó una cifra de trescientos edificios desocupados, en distinto grado de conservación, que en algunos barrios alcanzan un tercio del conjunto. Son sobre todo casas rurales, vivienda obrera y de autoconstrucción, en un arco amplio que va desde las casas de aldea de grandes dimensiones

\section{POBLACIÓN Y VIVIENDAS}

\begin{tabular}{lllllll}
\hline & Núcleos & $\begin{array}{l}\text { Población } \\
2019\end{array}$ & Edif. & Viv. & Fincas-50 m² & ${\text { Viv.-50 } \text { m }^{2}}$ \\
\hline Margen Izquierda & 18 & 832 & 555 & 784 & 129 & 210 \\
\hline Margen Derecha & 60 & 2.571 & 1.092 & 1.683 & 214 & 371 \\
\hline Total & 78 & 3.403 & 1.647 & 2.467 & 343 & 581 \\
\hline
\end{tabular}

TIPoLOGÍAS DE EDIFICACIÓN, ESTADO DE CONSERVACIÓN E INTERVENCIONES

\begin{tabular}{llllll}
\hline & Rural & $\begin{array}{l}\text { Urbana } \\
\text { Histórica }\end{array}$ & $\begin{array}{l}\text { Auto } \\
\text { Construcción }\end{array}$ & Desocupados & Rehabilitados \\
\hline Margen Izquierda & 54 & 59 & 78 & 101 & 50 \\
\hline Margen Derecha & 93 & 149 & 132 & 199 & 202 \\
\hline Total & 147 & 208 & 210 & 300 & 252
\end{tabular}

FECHAS CONSTRUCCIÓN \%

\begin{tabular}{lllllll}
\hline & $\begin{array}{l}\text { Cambio de } \\
\text { siglo y anterior }\end{array}$ & $\begin{array}{l}1^{\circ} \text { tercio } \\
\text { Siglo XX }\end{array}$ & Postguerra & Años 60-70 & Años 80-2000 Posteriores & P \\
\hline Margen Izquierda & 11,6 & 7,6 & 6,6 & 4,9 & 2,5 & 1,4 \\
\hline Margen Derecha & 28,4 & 7,7 & 10,8 & 13,4 & 2,9 & 1,7 \\
\hline Total & 40,1 & 15,3 & 17,4 & 18,4 & 5,4 & 3,1 \\
\hline
\end{tabular}

FIG. 6/ Tabla de estadísticas utilizadas. 
y una cierta distinción hasta los alojamientos más reducidos o aislados, con muy difícil salida en el mercado. Prueba de ello dan las numerosas propiedades en venta al menos desde 2012, según puede verse en Google Street Views, más las que van quedando vacías con el fallecimiento de sus propietarios, pertenecientes a la comunidad tradicional de mineros y trabajadores industriales jubilados; viviendas a las que todavía acuden de vez en cuando los descendientes, según múltiples testimonios. Aese fondo inmovilizado deben sumarse fósiles urbanos de mayor escala como el hospital de Murias, construido en la posguerra, y una industria cárnica en ruinas en El Batán.

En sentido inverso, más de doscientos cincuenta edificios ya han sido rehabilitados, mediante intervenciones someras o más raramente de una cierta profundidad ( $40 \%$ del total), tanto en fincas de interés cultural como del tipo corriente (ver FIG. 7). Obedecen a impulsos como las ayudas públicas a los antiguos residentes, y una creciente valoración de las casas de corredor u otros inmuebles de precio inferior a los pisos del centro, que atraen compradores hacia los barrios altos. Algunos de los cuales (La Rebollada, Rozaes de La Peña) han salido beneficiados con inversiones en redes técnicas y urbanización, procedentes de los Fondos de Reactivación del Plan del Carbón. Una vez reformadas por sus nuevos propietarios, las antiguas construcciones se utilizan como primera o segunda residencia, de grupos con renta casi siempre superior a los habitantes previos. Efecto similar tienen las cuarenta promociones de obra nueva levantadas en lo que va de siglo, mediante iniciativas dispersas o concentradas en ámbitos en remodelación (como las Casas de David), pues determinan una elevación del status social que puede resultar cercana a la gentrificación. EI Plan General de 1996 favorece las inversiones al conceptuar los espacios integrados físicamente en el

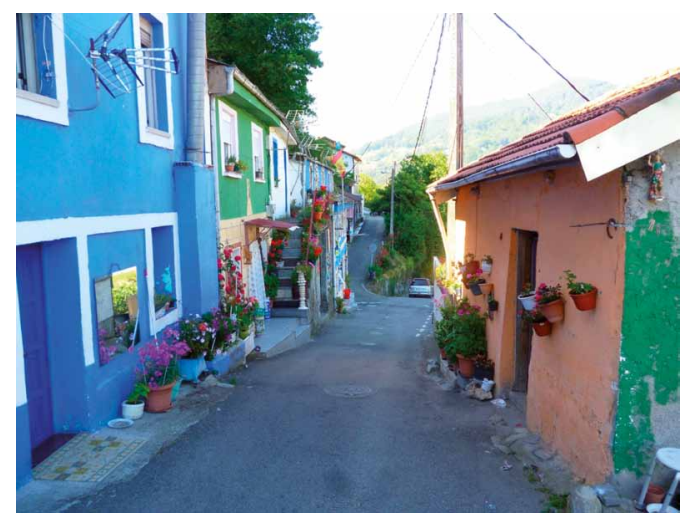

/ Rehabilitación somera en Sueros.

Fuente: Fotografía de Sergio TомÉ, 2019. casco como "zonas de desarrollo según alineaciones" o "zonas de edificación en borde de carretera"; reserva lo demás para edificación unifamiliar, fuera de las áreas protegidas como los parajes forestales.

Simplificando, pueden establecerse tres categorías de núcleos con arreglo a su evolución reciente. Unos son algo más activos y comparativamente más acomodados, en términos generales o de manera local (La Rebollada, El Rollu); suelen tener en común la buena conectividad (Siana), la amplitud de los valles laterales (Requejado, El Pedroso), y la situación a media ladera en el caso de las aldeas (Ladredo, Rozaes de Bazuelo). Sus atributos también pueden ser la cercanía al centro (Arriondo, Santa Clara) o una menor antigüedad (Los Pares). Pero casi nunca están ausentes en ellos los activos ociosos y la vivienda humilde, normalmente en las partes peor comunicadas o los escalones superiores.

Los barrios y aldeas relativamente más pobres, siquiera de forma parcial, y más fosilizados o regresivos, son de naturaleza diversa. Por regla general están a menor altitud, en contacto con la base del valle (La Peña, La Rampla) o en segunda fila de los edificios en pantalla asomados a las vías principales (Cantiquín, Paraxuela, Villa Alta) (ver FIG. 8). Cuando ocupan la margen izquierda del rio les afecta la barrera ferroviaria, con denso tráfico de trenes de cercanías que circulan a velocidad considerable (Sueros, La Fonda); otros tienen al pie instalaciones industriales (La Canterona, Cabanín, Arrojo), y algunos forman pequeños enclaves separados, como La Caleya o La Escombrera, donde habitan gitanos. El deterioro puede definir la totalidad del asentamiento (Arrojo) o solamente fracciones, normalmente coincidentes con los espacios más atomizados, interiores, con peor orientación y malas conexiones. El abandono del caserío, la urbanización deficiente y la falta de mantenimiento o la mala salubridad caracterizan algunos rincones de La Peña, la calle Nueva, La Villa Alta o Santullano, donde se percibe fácilmente que Mieres reúne el mayor contingente de población en riesgo de pobreza de la provincia (REGIOLAB, 2018). Un último grupo recoge las situaciones intermedias, propias de entidades de poblamiento más heterogéneas, complejas o difíciles de clasificar, aunque no siempre sean de tamaño considerable. Su casuística es bastante variada y muestran realidades bastante segmentadas, caso de Rozaes de La Peña o Ribono.

La actividad inmobiliaria y la llegada de residentes no han bastado para impedir que entre 2008 y 2018 la población cayese desde 4.442 hasta 3.982 habitantes (17\% del total de la ciudad), según el Padrón. El contingente es en realidad 


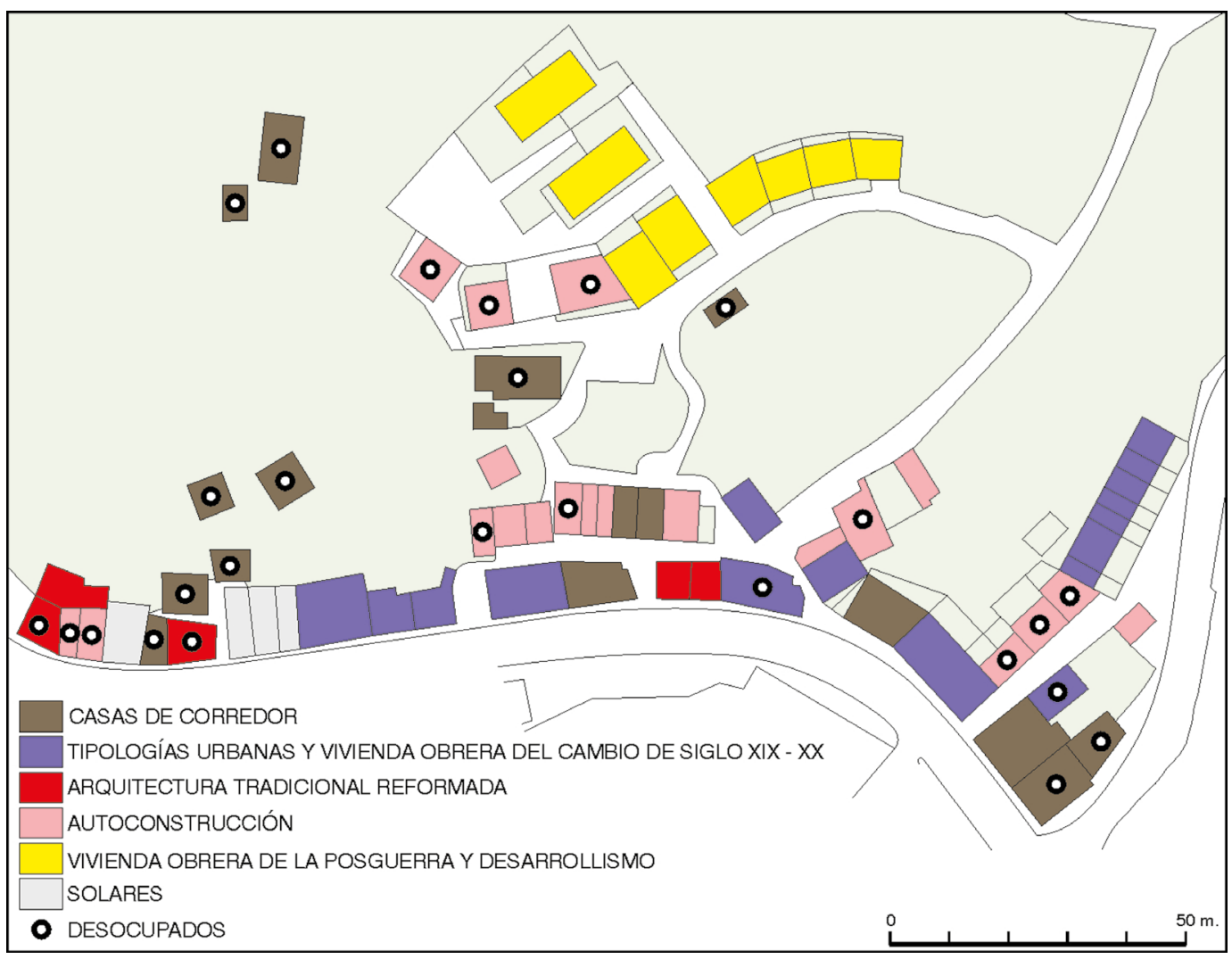

FIG. 8/ Detalle de la morfología, modelos edificatorios y nivel de desocupación en La Peña-La Rampla.

Fuente: Elaboración propia a partir del CATASTRO y conteo.

inferior, pues las secciones censales incluyen espacios exteriores al área de estudio, de manera que la cifra se rebaja hasta 3.403 habitantes si recurrimos al Nomenclátor, que también permite precisar suficientemente las variaciones a escala de detalle. El Padrón registra durante el último decenio pérdidas generalizadas, excepto en la parte adyacente al núcleo de la Villa, más cuantiosas (14-21\%) al extremo norte y sur de la mancha urbana; mientras, en las barriadas del fondo de valle la mengua era muy inferior $(7 \%)$, y el primer y segundo Ensanches incrementaban su censo un $36 \%$ por la sustitución de edificios antiguos. Cinco de las siete secciones censales tenían en 2016 una renta media por persona inferior al promedio municipal, siendo dos de ellas las más pobres del concejo, en los extremos septentrional y meridional del área urbana.

Al revés, el porcentaje de los mayores de 60 años llega a alcanzar el 29\% (24\% de media municipal) en la vertiente oriental y el $30-39 \%$ en la occidental, donde los extranjeros reúnen un $5 \%$ del total ( $2 \%$ en el centro). Precisamente allí se asentaron los primeros en llegar, desde Portugal, en el tramo central del siglo XX. El Nomenclátor permite matizar que, entre 2015 y 2019 , casi una treintena de entidades de población obtuvieron pequeñas ganancias. Sólo seis de ellas suman cantidades de cinco a nueve habitantes, valor que en Copián significa un $30 \%$ en términos relativos. Ese comportamiento diferenciado se da sobre todo en la aureola superior, con excepciones (Arriondo, Cantiquín). Al revés, las pérdidas superiores al $25 \%$ del total aparecen por regla general en la franja baja de las laderas, llegando a totalizar el $41 \%$ (La Caleya) y hasta el $50 \%$ (Camín de La Quinta) (ver FIG. 2).

\section{La habitabilidad y los problemas ambientales}

Las formas de vida son el resultado de la adaptación al relieve y están muy mediatizadas por la morfología catastral, los modelos de ocupación del terreno, así como el trabajo que realizan los 
miembros de la comunidad. El $44 \%$ de las fincas tienen superficies no superiores a $100 \mathrm{~m}^{2}$, y un $20 \%$ no alcanzan los 50 , porcentaje que se eleva hasta el $41 \%$ en La Peña o Rozaes de Bazuelo, y representa más de la mitad en La Rebollada. El minifundismo condiciona el tamaño de las viviendas, pues un $38 \%$ tienen dimensiones de entre 61 y $100 \mathrm{~m}^{2}$, pero la cuarta parte del total no suman ni $50 \mathrm{~m}^{2}$, habiendo más de un centenar que no rebasan los 30 . Son, en parte, cabañas, hábitat popular o resultante de repartos hereditarios, que en ocasiones dividen una casa de corredor en dos mitades, a las que se da tratamiento diferente. La falta de espacio obliga a disponer escaleras exteriores de acceso al piso situado en la planta superior, a veces muy empinadas, y provoca la multiplicación de pequeñas construcciones complementarias exentas (carbonera, cobertizo, garaje). Muchos alojamientos están estructurados en vertical, logran 45 o 55 $\mathrm{m}^{2}$ entre dos o tres alturas, cegando acaso los antiguos corredores. Cuando son más modernos ganan superficie habitable (hasta un $50 \%$ ) mediante porches y soportales, abiertos o cerrados, que funcionan como piezas de estancia, almacén o trastero. Existe si no el recurso de ocupar la vía pública con muebles (butacas, sillas) u otros enseres (tendedero, bicicletas), llevando incluso la caseta de las mascotas al otro lado del camino, donde también pueden verse, en las zonas más degradadas, viejos electrodomésticos abandonados y chatarra. La pequeñez, y en las propiedades mayores la vetustez y el escaso confort, del que dan prueba los retretes laterales en el corredor de las viejas casas rurales, jerarquizan notablemente los precios de venta ${ }^{3}$. En no pocos casos, la reforma que realizan los compradores consiste en fusionar dos o tres de las antiguas viviendas.

El mapa de usos continúa definido por la intercalación de huertos (parte de ellos incultos) y prados donde pastan ovejas o ganado equino, menos exigente que las vacas. Ese residuo del modelo tradicional no desaparece totalmente con el envejecimiento y la merma del contingente de los trabajadores industriales y mineros, que mantenían caserías al menos a tiempo parcial. A simple vista y según corroboran los testimonios recogidos en las entrevistas, el esquema se mantiene relativamente gracias al fenómeno de la segunda residencia, del que participan prejubilados relativamente más jóvenes y otros colectivos procedentes de la zona. Las funciones no residenciales están escasamente representadas, no habiendo otras dotaciones que un geriátrico

${ }^{3}$ En mayo de 2019 las casas más económicas estaban en Re-
senche $\left(74,2 \mathrm{~m}^{2} ; 13.300\right.$ euros) y Siana $\left(52 \mathrm{~m}^{2}\right.$ en dos plantas; privado (Siana), un consultorio de salud (La Rebollada) y tres escuelas reconvertidas en centros vecinales. Puede hablarse de sub-equipamiento en lo tocante al comercio y servicios de proximidad, dado que sólo existe una farmacia y menos de una treintena entre bares y pequeños comercios. La mayor parte de estos están situados en la base de la vertiente oriental, especialmente en Santullano, frontera del área de estudio, donde algunos negocios están cerrados, cosa que también ocurre en la margen opuesta.

Un condicionante muy destacado de la habitabilidad es la configuración deficiente de la red arterial, por su estrechez, irregularidad e inclinación (ver FIG. 9). Son frecuentes los caminos escarpados cuya parte superior está delimitada por sucesivos muros de contención fabricados al construir los edificios, para salvar pendientes temibles que están a la vista ladera abajo, a menudo sin parapeto o barandilla de protección. La mala accesibilidad, en sus diversos grados hasta el aislamiento (Norte, Gonzalín, Lavadero, Ribono, Cantiquín), debe medirse primero en términos de movilidad peatonal. La ausencia de aceras y las rampas acusadas dificultan los recorridos a pie, y el servicio de transporte público tiene ba-ja cobertura con frecuencias de paso superiores a la hora. Eso determina una dependencia del automóvil, aunque el viario entorpece el tránsito rodado y apenas proporciona espacios de estacionamiento; lo cual complica el abastecimiento (por ejemplo de gasóleo) y obliga a aparcar con aprietos en los desahogos de las vías públicas, obstaculizando la maniobra de otros vehículos.

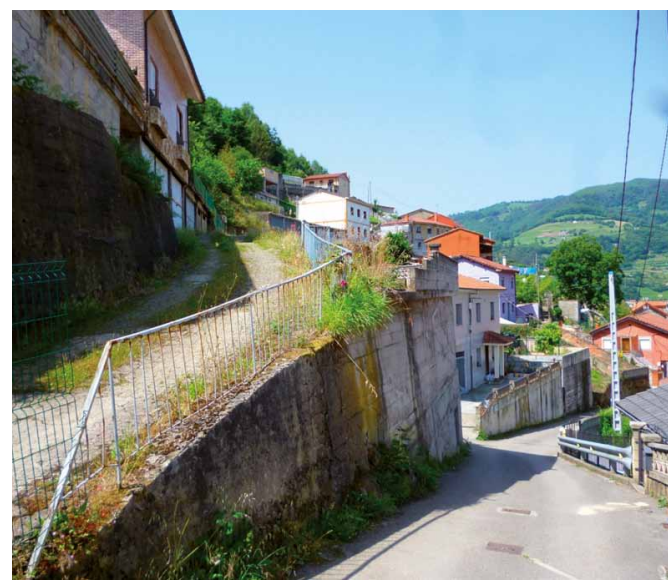

/ Rampas y muros de contención en Aguaín.

Fuente: Fotografía de Sergio TомÉ, 2019.

17.580 euros), según los portales inmobiliarios https://www.fotocasa.es y https://www.casa.toc.es 
Las personas mayores son las más perjudicadas por la dificultad de superar las escaleras exteriores de acceso a los pisos altos (apenas hay escaleras públicas de conexión interna) y la falta de espacio donde caminar con comodidad y seguridad. Sobre ese particular no es desdeñable la amenaza de los perros que defienden las fincas, convirtiendo a menudo cualquier recorrido en un suplicio. Súmense a eso las restricciones físicas y el fuerte impacto de los paredones laterales, así como las rampas y barandillas que rompen la continuidad espacial. Son sin embargo elementos consustanciales al paisaje, tanto como los cierres de aluminio o el alicatado de los edificios, generalizado durante décadas. Las duras condiciones de algunos núcleos o enclaves se ven aliviadas en otros por acciones públicas que insertan zonas verdes (Sueros), pequeños espacios públicos (Siana) y miradores que sacan partido del campo visual (El Pedroso, La Rampla).

A pesar de las deficiencias señaladas, el vecindario hace mucha vida de calle, aunque sea en la envolvente de su propiedad. También participa activamente en la mejora de unos parajes donde sorprende la alta frecuentación por ciclistas, interesados en las pendientes límite. Los allí afincados protagonizan prácticas de índole muy diversa, como la aplicación de placas decorativas para dar identidad a ciertos inmuebles, con el nombre del propietario o de la casa. También han costeado la instalación de barandillas en lugares de riesgo (Sueros), cuando la Administración no lo hacía, y de manera regular embellecen las vías públicas colocando un gran número de macetas que durante gran parte del año exhiben plantas en flor, dada la suavidad del clima. A ese respecto, los residentes tradicionales de los núcleos más populares opinan de forma bastante unánime que la gente de antes era más cuidadosa y tenía mayor pulcritud al cuidar la limpieza de los caminos y su ornato. La relación de ese grupo con su entorno físico y social parece mucho más rica, y su percepción más crítica respecto a los inconvenientes o el trato recibido del Ayuntamiento. Por el contrario, los recién llegados valoran casi exclusivamente la vivienda a la que han accedido o la distancia al centro, y suelen mostrarse más indiferentes hacia el colectivo. En los pequeños conjuntos de ciudad jardín, donde abundan los coches de alta gama, tampoco ausentes en otros asentamientos, la falta de civismo o el escaso sentido de pertenencia se interpretan más bien como un problema ajeno, propio de zonas menos acomodadas; en general allí preocupa más el riesgo de los robos, sin que exista una amenaza objetiva. En cuanto a los jóvenes, la encuesta reveló dos corrientes de opinión contrapuestas: unos se sienten encerrados o marginados en los barrios altos, otros los asocian con la libertad, la naturaleza o estilos de vida sencillos, sin que en uno u otro juicio parezca mediar el tiempo de estancia.

\section{Reflexiones finales}

En Mieres puede obtenerse una muestra significativa de las formas de urbanización y habitación características en las vertientes de los valles mineros asturianos. Allí aparecen superpuestos y entran en conflicto los escenarios de La Aldea Perdida (por la novela de Armando Palacio Valdés, publicada en 1903), los de la Revolución Industrial y el esplendor del carbón durante la Autarquía. No pocos de los asentamientos han perdido su contexto original (el alto horno, el pozo hullero, el taller), y eso obliga a realizar un esfuerzo añadido para darles sentido, aunque conservan las barreras físicas, elementos de rechazo, o simplemente continúan apartados y en su caso marginados. La amplitud del conjunto y sus acusados contrastes internos, debidos a la diferente posición relativa de cada núcleo y al efecto de la sedimentación histórica, dan como resultado una realidad muy parcelada, incluso dentro de cada entidad de población.

La evolución reciente parece dominada por dos fuerzas contradictorias, una tendente a la valoración económica y la rehabilitación, otra inexorablemente orientada al abandono y la depauperación, que acentúan las diferencias a escala meso y micro. La polaridad agudiza los problemas crónicos en ciertos lugares, pero tampoco basta para neutralizarlos por completo allí donde se reciben más inversiones. Así que en términos generales estamos ante un medio desorganizado, donde las redes resultan insuficientes, y hay deficiencias palpables en el alojamiento, la salubridad y los espacios públicos. Tampoco debe menospreciarse la exposición al riesgo de deslizamientos del terreno (argayos) y la eventualidad de que se declaren problemas estructurales en la edificación más básica, que ya se vivieron en la barriada de Rozaes de La Peña (Montañés, 2011).

De todo ello se desprende la necesidad de una acción regeneradora integral, entendida como articulación de medidas sectoriales (conexiones, seguridad, ruinas, patrimonio, vivienda vacante, servicios), a escala general o en forma de acupuntura para puntos precisos. La edificación de más interés, dada su doble condición rural y urbana, requiere un tratamiento selectivo que amplíe el catálogo de inmuebles protegidos y asegure su conservación, facilitando intervenciones no lesivas ni gentrificadoras. Ese es otro riesgo no despreciable, tras los proyectos de mejora, como 
se ha visto con el programa Favela Bairro en Río de Janeiro (DURÁN, 2018; MAKHLOUF, 2015). El resto de la arquitectura precisa soluciones a la carta, siendo inevitable el derribo de los elementos marginales, salvo una porción ilustrativa sobre las formas de vida del proletariado. Otra parte del fondo de viviendas deshabitadas es, pese a su carácter modesto y dimensiones reducidas, susceptible de adaptación mediante iniciativas experimentales. Que, apoyadas por el sector público, se desarrollarían en pequeños conjuntos o fragmentos del tejido, para ensayar nuevas soluciones habitacionales de bajo coste destinadas a los jóvenes.

Han de tomarse también como referencia las actuaciones en entornos relativamente parecidos de otras localidades, como Vigo (Teis) (ConCELLO DE VIGo, s. f.) o Bilbao, con su proyecto para la regeneración de áreas urbanas degradadas; allí ya ha comenzado la expropiación y derribo de casi cuatrocientas viviendas, cuyos habitantes son realojados en pisos de promoción pública situados en lugares más bajos (Ayuntamiento DE BILBAO, 2016, IPARRAGUIRRE, 2018). La capital vasca figura igualmente entre la decena de ciudades que han superado sus desniveles topográficos mediante escaleras mecánicas y ascensores, en zonas más céntricas o más densamente pobladas. Solución que en Mieres tropieza con el exiguo censo de los asentamientos y, en el caso de los más grandes, el carácter inapropiado o poco accesible de los espacios situados en la base. En un orden de cosas bien diferente, poner en marcha visitas guiadas podría servir para capitalizar los recursos ambientales o culturales (vistas, patrimonio etnográfico, cultura minera) de las casas colgadas y hacer más visibles sus necesidades. A tal efecto es interesante el plan de acción "A pie de Risco" en Las Palmas, inspirado al menos lejanamente en el Favela Tour carioca (Patronato de Turismo de Gran Canaria, 2019).

\section{Bibliografía}

ÁlvAREZ, C. (1986): Casa y carbón. La vivienda minera en la cuenca del Caudal, 1880-1936. Liño, n. ${ }^{\circ}$ 6: 83-99.

ayuntamiento de bilbao. Oficina de Planificación Urbana (2016): Avance del Plan General de Ordenación Urbana de Bilbao, Memoria Propositiva.

Ayuntamiento de Langreo (2011): Plan General de Ordenación urbana. Tomo I, Memoria de Información. https://www.langreo.as/

AYUNTAMIENTO DE LAS PALMAS; SOCIEDAD MUNICIPAL DE GESTIÓN URBANISTICA (GEURSA) (2018): Jornadas abiertas de participación vecinal "barrios pendientes". Ordenación y rehabilitación urbana de barrios en riscos. (13 noviembre-14 diciembre 2018). Memoria de participación. https://www.geursa.es
Ayuntamiento de Mieres (2016): Estadística de habitantes 2015. Habitantes por entidad colectiva y singular. http://www.mieres.es/

- (2019): Estadística de habitantes por poblaciones. http://www.mieres.es/

CAÑIZARES, C. (2001): El proceso de urbanización de la ciudad de Puertollano (Ciudad Real), Ciudad Real, Diputación provincial, Biblioteca de Autores Manchegos.

Castelli, P. (1996): Mieres, Población 1991. https://www.docplayer.es/

ceCodet, Centro de Cooperación y Desarrollo TERRITORIAL, (2016): Estrategia de Desarrollo Sostenible e Integrado de Mieres. Universidad de Oviedo. http://www.mieres.es/

Concello de Vigo (s.f.): Regeneración Urbana del barrio de Teis,

https://www.hoxe.vigo.org/movemonos/e pone teis. php?lang=cas\#/

Davis, M. (2007): Planeta de ciudades miseria, Madrid, Editorial Foca.

DURÁN, M. R. (2018): Desafíos para mejorar la urbanización integral de barrios marginales: el caso de los programas favela-bairro en Brasil. En Ciudades sostenibles, blog del Banco Interamericano de Desarrollo. https://(blogs.iadb.org/ciudades/ sostenibles/es/desafios-para-mejorar-los-programas-de-urbanizacion-integral-de-favelas/.

EsDRAs, M. (2008): Favelas en ciudades medias brasileñas: expansión y dificultad de medidas de control. Biblio 3W, Volumen XIII, n. ${ }^{\circ} 793$. http://www.ub.es/geocrit/b3w-793.htm

FERNÁNDEZ, S. (2015): Transformaciones territoriales recientes en el valle del Caudal como consecuencia de la reconversión industrial. Ribera de Arriba, Ayuntamiento.

Fernández, A. \& Fernández, M. (2016): “Diagnóstico sobre los principales problemas territoriales del Área Central de Asturias". En M. R. Alonso, Diagnóstico territorial e instrumentos para la regeneración urbanística integrada del Área Central de Asturias (pp. 19-55), Oviedo, Ediuno.

FonsECA, J. (1995): "Los orígenes de la minería y la siderurgia de Mieres". En J. León, Noticias históricas sobre Mieres y su concejo (pp. 491-516), Mieres, Ayuntamiento.

Gancedo, L. (2919): El síndrome de Mieres. Diario La Nueva España (7-abril-2019).

GARCiA, E. (1995): "Mieres, del ayer a la actualidad urbanística”. En J. León, Noticias históricas sobre Mieres y su concejo (pp. 305-341), Mieres, Ayuntamiento.

García, L. M. \& Pulido, T. (1980): Los barrios de urbanización marginal en Santa Cruz de Tenerife. Revista de Historia Canaria, n. ${ }^{\circ}$ 172: 157-204.

Gobierno de España, Ministerio de Fomento, Secretaría de Estado de Vivienda y Actuaciones URbanas (2011): Análisis urbanístico de barrios vulnerables. Madrid, Universidad Politécnica, Departamento de Urbanística y Ordenación del Territorio.

https://www.mitma.gob.es/areas-de-actividad/arquitectura-vivienda-y-suelo/urbanismo-y-politica-desuelo/observatorios-de-la-vulnerabilidad-urbana/ analisis-urbanistico-de-barrios-vulnerables 
Gobierno del Principado de Asturias (s.f.): Visor del Registro de Planeamiento y Gestión Urbanística. https://www.visorrpgur.asturias.es:8092/Visor Urbanismo RPGUR/Visor/VisorRPGUR.php

FernándeZ, A. \& al. (2009-2011): Análisis Urbanístico de barrios vulnerables. Ciudades para un futuro más sostenible.

https://www.habitat.aq.upm.es/bbvv/bbvv 148.html

Instituto Nacional de Estadística (INE): Estadística del Padrón Continuo 2008, 2018. https://www.ine.es/ -Atlas de Distribución de Renta de los Hogares, 2016. https://www.ine.es

IPARRAGUIRRE (S. N.) (2018): Chabolas, infravivienda y regeneración urbana.

https://arquitectura.com/2018/04/09/chabolas-infraviviendas-y-regeneracion-urbana/

León, J. (1995): Noticias históricas sobre Mieres y su concejo. Mieres, Ayuntamiento.

MAKHLOUF, M. (2015): "Aproximaciones a la gentrificación en el Río de Janeiro de los mega eventos deportivos". En V. Delgadillo, I. Diaz \& L. Salinas, Perspectivas del estudio de la gentrificación en México y América Latina (pp. 229-253), México, Instituto de Geografía, Universidad Nacional Autónoma.

MAURín, M. (1987): Introducción al estudio geográfico de las cuencas mineras españolas. Ería, nº 12:5-24.

- (2011): Huella, memoria y patrimonio territorial de la minería española: una síntesis cartográfica. Ería, $\mathrm{n}^{\circ}$ 86: 187-214.

Millán, P. B. \& Puentes, M. (2019): Ocupaciones al límite en topografías límite. Las "tomas" de Valparaíso (Chile). Ciudad y Territorio Estudios Territoriales, Volumen $n^{\circ}$ 201: 577-589.

MontAÑÉs, D. (2011): Los afectados por el derrumbe de La Peña reclaman el realojo de un discapacitado, Diario La Nueva España (21-junio-2019).

MoRo, S. (2014): Ejemplos de arquitectura social minera en Asturias en las décadas centrales del siglo XX. Trabajo Fin de Máster, Universidad de Oviedo. http://www.digibuo.uniovi.es/dspace/ bitstream/10651/39274/6/TFM SaraMoroGarcia.pdf

MuÑIz, N. (1885): Apuntes para la topografía médica del concejo de Mieres y de su comarca minera. https://www.bibliotecavirtual.asturias.es/i18n/ consulta/registro. $\mathrm{cmd}$ ? id $=387$

Patronato de Turismo de Gran Canaria (2019): El proyecto comunitario "A pie de risco» reinventa otras formas de turismo en los riscos de Las Palmas de Gran Canaria.

https://www.nuestrograndestino.es/el-proyecto-dedesarrollo-comunitario-a-pie-de-riscol

Pérez, R. (1980): Industria, población y desarrollo urbano en la Cuenca Central Hullera asturiana. Tesis Doctoral, Universidad de Oviedo, Departamento de Geografía.

- (1982): "Mieres". En F. QuiRós (dir.), Geografía de Asturias (pp. 75-133), Salinas, Ayalga Ediciones.

REGIOLAB. LABORATORIO de ANÁlIsIs ECONómico RegIONAL (2018): Dinámica espacial del riesgo de pobreza y exclusión en España y Asturias: análisis municipal. https://www.uniovi.net/regiolab/enlaces2/observatorio/n54/obs-REGIOlabjunio2018.pdf

Rodriguez, F. \& MenÉndez, R. (2005): Geografía de Asturias, Barcelona, Editorial Ariel.

- (2019): Contracción territorial y ordenación urbana para encarar el ciclo post-minero en Mieres (Asturias-España). Ciudades, n. ${ }^{\circ} 22$ : 99-122.

https://doi.org/10.24197/ciudades.22.2019.99-122

SANTA MARÍA, L. (2011): La favela como espacio de exclusión social en la ciudad de Rio de Janeiro. Eure, n. ${ }^{\circ}$ 110: 117-132.

http://dx.doi.org/10.4067/S0250716120110001000005

Sede Electrónica del Catastro (s.f.): Fondo mapa de España.

https://www1.sedecatastro.gob.es/Cartografíal mapa.aspx

SolÁ, M. (1973): Las formas del crecimiento urbano. Programa de la asignatura Urbanística 1, curso 1973-74. https://upcommons.upc.edu/

Alumnos del Colegio Claret (2010): El Risco de San Nicolás, un suburbio histórico de Las Palmas de Gran Canaria. Las Palmas de Gran Canaria, Biblioteca Universitaria. https://mdc.ulpgc.es/

VegA, J. A. (2015): Historia de Mieres. https://www.elsastredeloslibros.es 